\title{
IMPORTÂNCIA E DESEMPENHO DAS FLORESTAS PLANTADAS NO CONTEXTO DO AGRONEGÓCIO BRASILEIRO
}

\author{
José Mauro Magalhães Ávila Paz Moreira ${ }^{1 *}$, Flávio José Simioni ${ }^{2}$, Edilson Batista de Oliveira ${ }^{1}$ \\ 1* Embrapa Florestas, Colombo, Paraná, Brasil - jose-mauro.moreira@embrapa.br; edilson.oliveira@embrapa.br \\ ${ }^{2}$ Universidade do Estado de Santa Catarina, Programa de Pós-Graduação em Ciências Ambientais, Lages, Santa Catarina, Brasil - \\ flavio.simioni@udesc.br
}

Recebido para publicação: 12/07/2016 - Aceito para publicação: 19/12/2016

\begin{abstract}
Resumo
O objetivo deste trabalho é analisar a evolução das florestas plantadas no Brasil, considerando indicadores de custo de produção e rentabilidade em comparação as principais atividades agrícolas, bem como sua participação na balança comercial e na geração de empregos. A análise é histórica e utiliza dados estatísticos de agências nacionais. Os dados revelam que as florestas plantadas apresentam taxa de crescimento próximo da média mundial, porém com reduzida taxa de ocupação do solo quando comparada com lavouras e pastagens. Apresenta indicadores econômicos competitivos em relação a determinadas culturas agrícolas, cuja receita líquida pode variar de $-253,17$ a 523,79 R \$/ha.ano, dependendo das condições de produção e de mercado. No ambiente macroeconômico, representa importante contribuição no saldo positivo da balança comercial brasileira e na geração de empregos. Conclui-se que o segmento de florestas plantadas apresenta elevado impacto social e econômico para o Brasil, no entanto ainda pouco explorada considerando seu potencial produtivo e disponibilidade de terras, podendo representar um investimento atrativo para produtores rurais desde que bem planejadas.
\end{abstract}

Palavras-chave: Competitividade; setor florestal; culturas agrícolas.

\begin{abstract}
Importance and performance of planted forests in the context of Brazilian agribusiness. The aim of this study is to analyze the development of planted forests in Brazil, considering indicators of cost of production and profitability compared the main agricultural activities, as well as their participation in the trade balance and in the generation of jobs. The national statistical and data historical analysis were used. The data reveal that the showed planted forests growth rate close to the world average, but with a low rate of land occupation when compared to crops and pastures. Presents competitive economic indicators with regard to certain agricultural crops, whose net revenues can vary from -253.17 to $\mathrm{R} \$ 523.79 /$ ha.year, depending on the conditions of production and market. In the macroeconomic environment represents an important contribution in the positive balance of the Brazilian trade balance and in the generation of jobs. It has concluded that the segment of planted forests has a high social and economic impact for Brazil, but still little explored considering its productive potential and availability of land, and can represent an attractive investment for rural producers if well planned. Keywords: Competitiveness; forestry; agricultural crops.
\end{abstract}

\section{INTRODUÇÃO}

Os plantios florestais com espécies de rápido crescimento, principalmente com os gêneros Pinus e Eucaliptos, tiveram significativa expansão a partir dos anos 60, sobretudo no período de vigência dos incentivos fiscais, de 1966 a 1988 (KENGEN, 2001). Como resultado desse programa, as florestas plantadas passaram a suprir de forma crescente, inicialmente a demanda da indústria de celulose e papel e, posteriormente, de outros segmentos importantes tais como a produção de painéis, siderurgia e secagem de grãos.

Em um contexto histórico, é interessante observar o crescente suprimento de matéria prima pelas florestas plantadas em substituição a da extração vegetal de origem nativa. De acordo com dados da Produção da Extração Vegetal e da Silvicultura (PEVS) do IBGE (2014), a participação da lenha da silvicultura em relação ao total consumido passou de cerca de 20\% em 1990, para mais de 70\% em 2013. Apesar desse importante avanço, nos últimos anos o Brasil tem tido dificuldades para promover a expansão das florestas plantadas de uma forma duradoura.

Os investimentos em florestas plantadas apresentam algumas características que diferem bastante das culturas agrícolas em geral, como a ocorrência da maior parte dos custos das operações florestais desenvolvidas até a idade de corte se concentrarem na implantação do cultivo, e o retorno acontecer em apenas alguns períodos de tempo muitos anos após a implantação. Tais características podem reduzir a atratividade destes investimentos para produtores não habituados à cadeia produtiva florestal. Alguns fatores chaves como taxa de juros, custo de

FLORESTA, Curitiba, PR, v. 47, n. 1, p. 85 - 94, jan. / mar. 2017.

Moreira, J. M. M. Á. P. et al.

ISSN eletrônico 1982-4688

DOI: $10.5380 /$ rf.v47i1.47687 
arrendamento da terra e distância do consumidor afetam de maneira significativa a rentabilidade do cultivo florestal, devendo ser considerados cuidadosamente antes da decisão de implantar a floresta. Em contrapartida, a floresta pode ser manejada com diferentes finalidades, permitindo ao produtor alcançar diferentes mercados de produtos florestais, e a data de colheita pode variar em alguns anos, não sendo obrigatória a colheita em uma determinada época como as safras agrícolas. Esta característica permite ao produtor florestal uma certa flexibilidade para a colheita da floresta, possibilitando postergar a comercialização do seu produto para um momento, caso as condições atuais do mercado não estejam favoráveis.

Nesse contexto, este trabalho nasceu de uma iniciativa dos autores considerando a demanda das organizações relacionadas às florestas plantadas com o objetivo de analisar a evolução das florestas plantadas no Brasil, considerando indicadores de custo de produção e rentabilidade em comparação as principais atividades agrícolas, bem como sua participação na balança comercial e na geração de empregos. Para tanto, foi necessário retroceder temporalmente e buscar dados a respeito da evolução das principais culturas agrícolas e de florestas plantadas, buscando estabelecer análises comparativas entre elas.

Optou-se por dividi-lo em quatro seções, sendo a primeira, esta introdução. Na seção dois, expõe-se os procedimentos metodológicos e a fonte dos dados utilizados nas análises. Na seção seguinte, de número três, apresenta-se a evolução das florestas plantadas no mundo e no Brasil e uma análise de indicadores de desempenho econômico comparativamente as principais culturas agrícolas. Por fim, nas conclusões são indicados aspectos importantes para a manutenção do crescimento desse setor.

\section{MATERIAL E MÉTODOS}

O método de análise para a realização desse trabalho foi o descritivo, utilizando-se da pesquisa documental para explorar as relações conceituais já conhecidas e disponibilizadas em artigos especializados. $\mathrm{O}$ tratamento dos dados ocorreu de forma quantitativa e a abordagem do tema se deu de maneira histórica, o que também caracteriza o estudo como longitudinal, com período de análise definido. Para caracterizar o desempenho das florestas plantadas no Brasil utilizou-se de um conjunto de indicadores, tais como a área plantada, produtividade, custos e receita em comparação com as principais culturas agrícolas, como também sua participação na balança comercial e na geração de empregos.

A evolução histórica da área cultivada com florestas no mundo, considerando dados do Global Forest Resources Assessement da Food and Agriculture Organization of the United Nations (FAO), foi avaliada em cinco períodos: 1990, 2000, 2005, 2010 e 2015. Para analisar a evolução do uso da terra no Brasil, considerou-se os dados do censo agropecuário do Instituto Brasileiro de Geografia e Estatística (IBGE) disponíveis a partir de 1970, considerando a taxa geométrica de crescimento $(\mathrm{g})$, obtida a partir da equação:

$$
g=\sqrt[n]{\frac{V_{n}}{V_{o}}}-1
$$

em que: Vn = último valor observado da série; Vo = primeiro valor observado da série; e $\mathrm{n}$ = número de períodos da série.

Os dados de área plantada e colhida, produção e valor bruto da produção das principais culturas agrícolas do Brasil foram obtidos a partir da Produção Agrícola Municipal (PAM) (IBGE, 2013), da Pesquisa da Extração Vegetal e Silvicultura (PEVS) (IBGE, 2014) e do banco de dados da Indústria Brasileira de Árvores (IBÁ, 2014). Para as culturas permanentes foi considerado a área destinada à colheita em 2013 e, no caso das florestas plantadas, a estimativa da área de colheita considerou um ciclo de produção de 7 (sete) anos para o eucalipto e 15 anos para o pinus e outras espécies.

Os custos de produção, produtividade e rentabilidade de culturas agrícolas selecionadas do Brasil foram obtidos da Companhia Nacional de Abastecimento (CONAB, 2015a). A Receita Bruta (RB) foi calculada a partir dos dados dos sistemas de produção disponíveis na CONAB para as safras de 2013 e 2014, considerando a produtividade e o preço médio nominal dos meses de dezembro de 2013 e 2014 e agosto de 2014 (CONAB, 2015b). A Receita Líquida (RL) foi obtida subtraindo da RB o Custo Total (CT).

Para a obtenção da Receita Líquida Anual das florestas plantadas foi considerado a cultura de eucalipto com finalidade de produção de lenha, vendida em pé, em diferentes cenários de produtividade, taxa de juros, custo da terra e preço de venda da madeira. Os custos foram levados para o momento do corte raso $\left(7^{\circ}\right.$ ano), sendo calculada a Receita Líquida Total por hectare e depois dividida pela duração do ciclo de sete anos, possibilitando a comparação com as culturas anuais. Quanto a produtividade, foi considerado plantio de eucalipto de alta tecnologia, com produtividade semelhante à média nacional, ou seja, Incremento Médio Anual (IMA) de $38,1 \mathrm{~m}^{3} /$ ha.ano e de média a baixa tecnologia, com produtividade $25 \%$ inferior, de $28,6 \mathrm{~m}^{3} / \mathrm{ha}$.ano (CEDAGRO, 2015). O custo da terra foi calculado considerando dois valores para arrendamento (R $\$ 200,00 \mathrm{e}$ 
$\mathrm{R} \$ 300,00 /$ ha.ano). Já o custo dos juros foi calculado a partir da diferença entre o valor futuro [VF=VC* $(1+\mathrm{k})^{\mathrm{t}}$ ] dos custos de produção (desembolsos) e o valor dos mesmos a preços constantes (VC), onde k é a taxa real de juros (\% ao ano) e t é o tempo.

Os dados da balança comercial dos produtos florestais foram obtidos do sistema AgroStat do Ministério da Agricultura, Pecuária e Abastecimento (MAPA) (BRASIL, 2015a) e do sistema AliceWeb2 da Secretaria de Comércio Exterior do Ministério do Desenvolvimento, Indústria e Comércio (SECEX) do Ministério do Desenvolvimento, Indústria e Comércio Exterior (MDIC) (BRASIL, 2015b). Já os dados de emprego foram obtidos do Serviço Florestal Brasileiro - Sistema Nacional de Informações Florestais (SNIF) e o potencial de geração de empregos foi estimado de acordo com o modelo proposto por Nadjberg e Pereira (2004).

\section{RESULTADOS}

A área de florestas plantadas no mundo tem aumentado anualmente cerca de 4,73 milhões de hectares nos últimos vinte e cinco anos (FAO, 2015). Os propósitos de tais plantios são variados, mas estima-se que em $76 \%$ destas florestas o foco é a produção florestal (FAO, 2010). Conforme pode ser observado na tabela 1 , China, Estados Unidos e Rússia possuem mais de $41 \%$ das florestas plantadas no mundo. Contudo, os países que aumentaram sua participação percentual de 1990 a 2015 foram a China, Canadá, Suécia e Índia. O Brasil tem aumentado a sua área de florestas plantadas, mas a uma taxa geométrica média (TGM) anual de 1,8\%, inferior à taxa mundial $(2,1 \%)$. Atualmente, o país ocupa a nona posição em termos de área plantada de florestas, respondendo por menos de $3 \%$ dos plantios florestais do mundo.

Tabela 1. Evolução da área de florestas plantadas no mundo entre 1990-2015.

Table 1. Evolution of forest area planted in the world between 1990-2015.

\begin{tabular}{|c|c|c|c|c|c|c|c|c|}
\hline \multirow[t]{2}{*}{ País } & \multicolumn{5}{|c|}{ Área de florestas plantadas(1000 ha) } & \multicolumn{2}{|c|}{$\begin{array}{c}\begin{array}{c}\text { Participação na Área } \\
\text { global }(\%)\end{array} \\
\end{array}$} & \multirow{2}{*}{$\begin{array}{c}\text { TGM } \\
\text { (a.a.) }\end{array}$} \\
\hline & 1990 & 2000 & 2005 & 2010 & 2015 & 1990 & 2015 & \\
\hline China & 41.950 & 54.394 & 67.219 & 73.067 & 78.982 & $23,82 \%$ & $27,27 \%$ & $2,6 \%$ \\
\hline Estados Unidos & 17.938 & 22.560 & 24.425 & 25.564 & 26.364 & $10,19 \%$ & $9,10 \%$ & $1,6 \%$ \\
\hline Rússia & 12.651 & 15.360 & 16.963 & 19.613 & 19.841 & $7,18 \%$ & $6,85 \%$ & $1,8 \%$ \\
\hline Canadá & 4.578 & 9.345 & 11.710 & 13.975 & 15.784 & $2,60 \%$ & $5,45 \%$ & $5,1 \%$ \\
\hline Suécia & 7.399 & 9.839 & 11.099 & 12.564 & 13.737 & $4,20 \%$ & $4,74 \%$ & $2,5 \%$ \\
\hline Índia & 5.716 & 7.167 & 9.486 & 11.139 & 12.031 & $3,25 \%$ & $4,15 \%$ & $3,0 \%$ \\
\hline Japão & 10.287 & 10.331 & 10.324 & 10.292 & 10.270 & $5,84 \%$ & $3,55 \%$ & $0,0 \%$ \\
\hline Polônia & 8.511 & 8.645 & 8.767 & 8.877 & 8.957 & $4,83 \%$ & $3,09 \%$ & $0,2 \%$ \\
\hline Brasil & 4.984 & 5.176 & 5.620 & 6.973 & 7.736 & $2,83 \%$ & $2,67 \%$ & $1,8 \%$ \\
\hline Finlândia & 4.390 & 4.953 & 5.901 & 6.775 & 6.775 & $2,49 \%$ & $2,34 \%$ & $1,8 \%$ \\
\hline Sudão & 5.424 & 5.639 & 5.854 & 5.940 & 6.121 & $3,08 \%$ & $2,11 \%$ & $0,5 \%$ \\
\hline Alemanha & 5.388 & 5.416 & 5.278 & 5.290 & 5.295 & $3,06 \%$ & $1,83 \%$ & $-0,1 \%$ \\
\hline Outros & 46.902 & 59.431 & 67.830 & 77.126 & 77.706 & $26,63 \%$ & $26,83 \%$ & $2,0 \%$ \\
\hline Total & 171.332 & 214.619 & 242.960 & 264.001 & 289.599 & $100,0 \%$ & $100,0 \%$ & $2,1 \%$ \\
\hline
\end{tabular}

Fonte: Global Forest Resources Assessement - FRA2015 (FAO, 2015).

O território nacional possui 851,48 milhões de hectares, sendo que a sua ocupação agrícola passou de 246 milhões de hectares em 1970 para 317 milhões em 2006, aumentando a área de uso agrícola em 28,86\%, passando a ocupar 37,35\% da área do país (Tabela 2).

Tabela 2. Evolução da utilização das terras da agricultura no Brasil entre 1970 e 2006 (em hectares).

Table 2. Evolution of land use of farms in Brazil between 1970 and 2006 (in hectares).

\begin{tabular}{|c|c|c|c|c|c|c|}
\hline Destinação & 1970 & 1975 & 1980 & 1985 & 1996 & 2006 \\
\hline Lavouras permanentes & 7.984 .059 & 8.385 .390 & 10.472 .124 & 9.903 .472 & 7.541 .626 & 11.612 .229 \\
\hline Lavouras temporárias & 25.999 .716 & 31.616 .239 & 38.605 .107 & 42.244 .210 & 34.252 .828 & 48.234 .389 \\
\hline Matas naturais & 56.222 .951 & 67.857 .524 & 83.151 .970 & 83.016 .962 & 88.897 .583 & 93.982 .304 \\
\hline Florestas plantadas & 1.658 .226 & 2.864 .300 & 5.015 .700 & 5.966 .612 & 5.396 .013 & 4.497.322 \\
\hline Pastagens naturais & 124.405 .933 & 125.950 .591 & 113.897 .035 & 105.094 .014 & 78.048 .464 & 57.316 .459 \\
\hline Pastagens plantadas & 29.732 .297 & 39.701 .360 & 60.602 .271 & 74.094 .390 & 99.652 .011 & 101.437 .411 \\
\hline Total Geral & 246.003 .182 & 276.375 .404 & 311.744.207 & 320.319 .660 & 313.788 .525 & 317.080 .114 \\
\hline
\end{tabular}

Fonte: Séries históricas e estatísticas - utilização das terras (ha) do IBGE (2015). 
No período 1970-2006, a área nacional com florestas plantadas aumentou 171\%, principalmente em decorrência das oportunidades geradas pelo desenvolvimento do setor florestal brasileiro e pela necessidade de substituição de madeira de origem nativa pela madeira de florestas plantadas para usos energéticos e industriais. Entretanto, este elevado aumento em termos percentuais decorre da área muito reduzida de florestas plantadas em 1970. Em termos absolutos, as florestas plantadas apresentaram o segundo pior incremento em ocupação das áreas nacionais, sendo superior apenas ao de pastagens nativas. A área com florestas plantadas apresentou um aumento médio anual de 78,8 mil hectares, bem inferior aos 100 mil hectares anuais de lavouras permanentes, 617 mil de lavouras temporárias, 1 milhão de hectares de matas naturais e 1,99 milhões de pastagens plantadas. A diferença entre os dados da FAO e o IBGE pode ser decorrente da fonte de informação utilizada e do período de tempo que as informações estavam disponíveis. O Forest Resource Assessment (FRA) da FAO é preenchido pelos países ou por especialistas com as informações florestais de cada país, e são enviados para a FAO para compor o FRA, o qual é atualizado a cada cinco anos. Os dados do IBGE resultam dos censos agropecuários, onde o último realizado foi em 2006, e cujos resultados ficaram disponíveis apenas em 2007. Até o ano de 2006, era difícil uma publicação com a estimativa da área anual de florestas plantadas no Brasil, quando foi publicado o primeiro Anuário Estatístico da ABRAF (ABRAF, 2006), sendo que o IBGE passou a contabilizar a área anual de florestas plantadas na PEVS a partir de 2013. Atualmente contamos com duas fontes de dados sobre a área de florestas plantadas no Brasil, o Relatório Anual da Indústria Brasileira de Árvores (IBÁ) e a PEVS do IBGE.

A tabela 3 apresenta a área plantada, colhida, a quantidade produzida e o valor bruto da produção (VBP) por área das principais culturas agrícolas em 2013. Os plantios florestais são a quarta maior cultura com área plantada, menor apenas que a soja, o milho e a cana-de-açúcar. Entretanto, a área disponível para colheita é significativamente inferior a este valor, uma vez que a rotação de florestas de eucalipto geralmente dura sete anos e as de pinus e outras espécies plantadas com finalidade de madeira, pelo menos 15 anos. Considerando esses ciclos médios de produção florestal, e que as áreas sejam bem distribuídas pelas diferentes idades da floresta, pode-se estimar que a área disponível para colheita seja próxima a 920 mil hectares por ano, aproximando as florestas plantadas às culturas de algodão e sorgo em termos de área disponível para colheita.

A colheita da floresta para produção de madeira representa a exaustão de um investimento de 7 (sete) ou pelo menos 15 anos, gerando um valor bruto médio da produção por hectare colhido relativamente elevado, acima de R\$ 15 mil por hectare, considerando a área estimada de colheita. Entretanto, a comparação com as culturas agrícolas foi realizada em termos de VBP anual, o que demonstra que as florestas plantadas possuem um dos menores valores de produção (VP) por área colhida em relação à maioria das culturas (Tabela 3).

Entretanto, o custo de produção florestal é reduzido quando comparado às principais culturas agrícolas, e cerca de $70 \%$ do custo da floresta em pé é desembolsado no momento de sua implantação. Uma maneira mais apropriada para comparação dos plantios florestais com os plantios agrícolas pode ser realizada utilizando-se da receita líquida esperada pelo produtor.

Tabela 3. Área, produção e valor bruto da produção das principais culturas agrícolas do Brasil - 2013.

Table 3. Area, production and gross value of production of the main crops in Brazil - 2013.

\begin{tabular}{|c|c|c|c|c|c|}
\hline $\begin{array}{l}\text { Principais produtos das lavouras } \\
\text { temporárias e permanentes }\end{array}$ & $\begin{array}{c}\text { Área plantada } \\
\text { ou destinada à } \\
\text { colheita (ha) }\end{array}$ & $\begin{array}{l}\text { Área colhida } \\
\text { (ha) }\end{array}$ & $\begin{array}{l}\text { Quantidade } \\
\text { produzida } \\
\left(\text { t ou m }^{3}\right) \\
\end{array}$ & $\begin{array}{c}\text { Valor da produção } \\
\text { (VP) } \\
(1.000 \mathrm{R} \$) \\
\end{array}$ & $\begin{array}{l}\text { VP anual por } \\
\text { área colhida } \\
(\mathrm{R} \$ / \mathrm{ha} . \mathrm{ano}) \\
\end{array}$ \\
\hline TOTAL & 72.737 .134 & 71.294 .379 & $\ldots$ & 232.468 .993 & \\
\hline Lavouras Temporárias & 66.406 .024 & 65.396 .271 & $\ldots$ & 196.083 .410 & \\
\hline Lavouras Permanentes & 6.331 .110 & 5.898 .108 & $\ldots$ & 36.385 .583 & \\
\hline Soja (em grão) & 27.948 .605 & 27.906 .675 & 81.724 .477 & 68.934 .363 & $2.470,17$ \\
\hline Milho (em grão) & 15.708 .367 & 15.279 .652 & 80.273 .172 & 26.723 .097 & $1.748,93$ \\
\hline Cana-de-açúcar ${ }^{1}$ & 10.223 .043 & 10.195 .166 & 768.090 .444 & 42.946 .610 & $4.212,45$ \\
\hline Feijão (em grão) & 3.041 .299 & 2.813 .506 & 2.892 .599 & 6.945 .595 & $2.468,66$ \\
\hline Arroz (em casca) & 2.386 .821 & 2.353 .152 & 11.782 .549 & 7.545 .033 & $3.206,35$ \\
\hline Trigo (em grão) & 2.225 .401 & 2.087.395 & 5.738 .473 & 3.809 .304 & $1.824,91$ \\
\hline Café (beneficiado) ${ }^{1}$ & 2.094 .257 & 2.085 .522 & 2.964 .538 & 12.820 .331 & $6.147,30$ \\
\hline Mandioca $^{1}$ & 1.560 .263 & 1.525 .918 & 21.484 .218 & 10.130 .512 & $6.638,96$ \\
\hline Algodão herbáceo (em caroço) & 946.406 & 943.742 & 3.417 .196 & 6.923 .887 & $7.336,63$ \\
\hline Sorgo granífero (em grão) & 802.020 & 792.838 & 2.126 .179 & 535.796 & 675,80 \\
\hline Laranja $^{1}$ & 719.360 & 702.200 & 17.549 .536 & 4.765 .624 & $6.786,70$ \\
\hline Castanha de caju $^{1}$ & 708.808 & 695.289 & 109.679 & 160.294 & 230,54 \\
\hline Cacau (em amêndoa) ${ }^{1}$ & 692.435 & 689.276 & 256.186 & 1.214 .038 & $1.761,32$ \\
\hline Banana $^{1}$ & 490.628 & 485.075 & 6.892 .622 & 5.114 .223 & $10.543,16$ \\
\hline Outros & 2.480 .750 & 2.333 .720 & 29.368 .376 & 28.269 .120 & - \\
\hline Florestas plantadas ${ }^{2,3}$ & 7.600 .974 & - & 229.896 .746 & 14.094 .763 & $1.854,34$ \\
\hline
\end{tabular}

Fonte: Elaborado pelos autores a partir de dados da Produção Agrícola Municipal (IBGE, 2013), Pesquisa da Extração Vegetal e da Silvicultura (IBGE, 2014) e do IBÁ (2014). Notas: 1) Área destinada à colheita em 2013. 2) Quantidade produzida e valor da produção 
obtidos na Pesquisa da Extração Vegetal e da Silvicultura (IBGE, 2014) e área plantada do IBÁ (2014). 3) O cálculo do valor da produção das florestas plantadas considerou a quantidade produzida de madeira em tora, lenha e carvão vegetal da silvicultura (1 tonelada de carvão $=$ 7,845 $\mathrm{m}^{3}$ de madeira - LIMA et al., 2012).

A receita líquida das culturas agrícolas apresenta significativa amplitude em seus resultados (Tabela 4). Enquanto a soja, o feijão e o café apresentaram os melhores resultados das culturas selecionadas, o milho safrinha, trigo e algodão apresentaram receita líquida negativa. É importante observar que os resultados das receitas líquidas dependem de diferentes fatores, tais como as condições de clima e de mercado. No caso do algodão, houve recuo nos preços do período analisado. Para o milho safrinha, tal sistema de produção deve ser analisado em conjunto com a cultura da soja, uma vez que seu plantio ocorre em sucessão e configura-se numa alternativa de uso do solo no período da entressafra. Já o trigo sofreu uma queda significativa dos preços decorrente do excesso de oferta de trigo importado devido à redução do imposto de importação.

Tabela 4. Custos de produção, produtividade e rentabilidade de culturas agrícolas selecionadas do Brasil. Table 4. Production costs, productivity and profitability of selected agricultural crops in Brazil.

\begin{tabular}{|c|c|c|c|c|c|c|}
\hline $\begin{array}{l}\text { Culturas } \\
\text { Selecionadas }\end{array}$ & $\begin{array}{l}\text { Custo Total } \\
\text { (R\$/ha) (a) }\end{array}$ & $\begin{array}{c}\text { Custo } \\
\text { Operacional } \\
(\mathbf{R} \$ / \mathrm{ha})(\mathbf{b})\end{array}$ & $\begin{array}{l}\text { Produtividade } \\
\text { (kg/ha) (c) }\end{array}$ & $\begin{array}{c}\text { Preço } \\
(\mathbf{R} \$ / \mathbf{k g})(\mathbf{d})\end{array}$ & $\begin{array}{c}\text { Receita Bruta } \\
(\mathrm{R} \$ / \mathrm{ha})(\mathrm{e}=\mathrm{c.d})\end{array}$ & $\begin{array}{c}\text { Receita } \\
\text { Líquida } \\
(\mathbf{R} \$ / \mathbf{h a})(\mathbf{e}-\mathbf{a})\end{array}$ \\
\hline Café arábica & $\mathrm{R} \$ 10.474,41$ & $\mathrm{R} \$ 9.953,63$ & $1.800,00$ & $\mathrm{R} \$ 6,27$ & $\mathrm{R} \$ 11.292,50$ & $\mathrm{R} \$ 818,09$ \\
\hline Feijão & $\mathrm{R} \$ 3.468,34$ & $\mathrm{R} \$ 3.103,19$ & $2.725,00$ & $\mathrm{R} \$ 1,58$ & $\mathrm{R} \$ 4.286,03$ & $\mathrm{R} \$ 817,70$ \\
\hline Soja & $\mathrm{R} \$ 2.238,00$ & $\mathrm{R} \$ 2.026,02$ & $3.068,00$ & $\mathrm{R} \$ 0,99$ & $\mathrm{R} \$ 3.022,25$ & $\mathrm{R} \$ 784,25$ \\
\hline Mandioca & $\mathrm{R} \$ 6.318,12$ & $\mathrm{R} \$ 5.803,55$ & $30.992,00$ & $\mathrm{R} \$ 0,22$ & $\mathrm{R} \$ 6.765,09$ & $\mathrm{R} \$ 446,97$ \\
\hline Arroz & $\mathrm{R} \$ 4.988,76$ & $\mathrm{R} \$ 4.484,20$ & $7.490,00$ & $\mathrm{R} \$ 0,71$ & $\mathrm{R} \$ 5.341,87$ & $\mathrm{R} \$ 353,10$ \\
\hline Milho safrinha & $\mathrm{R} \$ 1.780,43$ & $\mathrm{R} \$ 1.351,02$ & $5.625,00$ & $\mathrm{R} \$ 0,24$ & $\mathrm{R} \$ 1.360,31$ & $-\mathrm{R} \$ 420,12$ \\
\hline Trigo & $\mathrm{R} \$ 2.178,10$ & $\mathrm{R} \$ 1.752,79$ & $2.660,00$ & $\mathrm{R} \$ 0,55$ & $\mathrm{R} \$ 1.457,80$ & $-\mathrm{R} \$ 720,30$ \\
\hline Algodão (pluma) & $\mathrm{R} \$ 7.250,62$ & $\mathrm{R} \$ 6.163,51$ & $1.620,00$ & $\mathrm{R} \$ 3,90$ & $\mathrm{R} \$ 6.318,18$ & $-\mathrm{R} \$ 932,44$ \\
\hline
\end{tabular}

Fonte: CONAB (2015a; 2015b). Nota: A rentabilidade foi calculada a partir de dados de sistemas de produção disponíveis na CONAB para as safras de 2013 e 2014, considerando um preço médio dos meses de dezembro de 2013 e 2014 e agosto de 2014.

Mesmo assim, como os custos das atividades florestais são inferiores aos custos de produção das principais culturas agrícolas, de maneira que a receita líquida obtida pode igualar ou até superar as receitas de atividades agrícolas, tanto em solos de baixa como de média produtividade, as atividades florestais tornam-se competitivas (Tabelas 5). Os resultados ilustram que plantios florestais podem ter rentabilidade variando de 253,17 a 523,79 R $\$$ /ha.ano, demonstrando ser competitiva quando comparada a algumas culturas agrícolas.

Tabela 5. Indicadores econômicos da cultura de eucalipto para lenha, vendida em pé, em diferentes cenários. Table 5. Economic indicators of eucalyptus culture for wood, sold standing in different scenarios.

\begin{tabular}{|c|c|c|c|c|c|c|c|}
\hline \multirow{2}{*}{$\begin{array}{l}\text { Sistema de } \\
\text { Produção }\end{array}$} & \multirow{2}{*}{$\begin{array}{c}\text { T.M.A. } \\
\text { real } \\
\text { (ao ano) }\end{array}$} & \multirow{2}{*}{$\begin{array}{c}\text { Desembolso } \\
\text { ( } \mathrm{R} \$ / \text { ha } \\
\text { em } 7 \text { anos) }\end{array}$} & \multirow{2}{*}{$\begin{array}{c}\text { Terra }^{1} \\
\text { (R\$/ha } \\
\text { em } 7 \text { anos) }\end{array}$} & \multirow{2}{*}{$\begin{array}{c}\text { Juros }^{2} \\
\text { (R\$/ha } \\
\text { em } 7 \text { anos) } \\
\end{array}$} & \multirow{2}{*}{$\begin{array}{c}\text { Custo Total } \\
\text { (R\$/ha } \\
\text { em } 7 \text { anos) }\end{array}$} & \multicolumn{2}{|c|}{ Receita Líquida Anual (R\$/ha.ano) } \\
\hline & & & & & & $\begin{array}{c}\text { Preço }\left(\mathrm{R} \$ / \mathrm{m}^{3}\right) \\
45,00\end{array}$ & $\begin{array}{c}\text { Preço }\left(\mathrm{R} \$ / \mathrm{m}^{3}\right) \\
32,00\end{array}$ \\
\hline \multirow{4}{*}{ 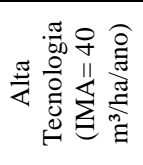 } & \multirow{2}{*}{$3 \%$} & \multirow{4}{*}{$6.234,83$} & $1.400,00$ & $1.298,66$ & $8.933,48$ & 523,79 & 3,79 \\
\hline & & & $2.100,00$ & $1.364,90$ & $9.699,73$ & 414,32 & $-105,68$ \\
\hline & \multirow{2}{*}{$5 \%$} & & $1.400,00$ & $2.283,17$ & $9.917,99$ & 383,14 & $-136,86$ \\
\hline & & & $2.100,00$ & $2.397,37$ & $10.732,19$ & 266,83 & $-253,17$ \\
\hline \multirow{4}{*}{ 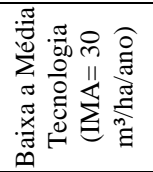 } & \multirow{2}{*}{$3 \%$} & \multirow{4}{*}{$5.159,47$} & 700,00 & 994,24 & $6.853,71$ & 370,90 & $-19,10$ \\
\hline & & & $1.400,00$ & $1.060,49$ & $7.619,96$ & 261,43 & $-128,57$ \\
\hline & \multirow{2}{*}{$5 \%$} & & 700,00 & $1.745,25$ & $7.604,72$ & 263,61 & $-126,39$ \\
\hline & & & $1.400,00$ & $1.859,45$ & $8.418,92$ & 147,30 & $-242,70$ \\
\hline
\end{tabular}

Fonte: Dados calculados pelos autores considerando um plantio de eucalipto de alta tecnologia, com produtividade semelhante à média nacional (38,1 m³/ha/ano) e um de média a baixa tecnologia, com produtividade $25 \%$ inferior (CEDAGRO, 2015). Notas: 1) O custo da terra foi calculado considerando dois valores para arrendamento (R $\$ 200,00$ e $\mathrm{R} \$ 300,00 / \mathrm{ha} / \mathrm{ano}$ ). 2) O custo dos juros foi calculado a partir da diferença entre a soma dos custos de produção capitalizados para o final do ciclo (valor futuro) e a soma dos seus valores não capitalizados (a preços constantes).

O setor florestal também contribui de maneira significativa para a balança comercial do país. Em 2014 os produtos florestais contribuíram com 10,2\% das exportações do agronegócio e com 4,42\% das exportações nacionais. Além disso, o setor importa menos do que exporta, sendo responsável por 9,3\% do saldo da balança comercial do agronegócio (Tabela 6).

FLORESTA, Curitiba, PR, v. 47, n. 1, p. 85 - 94, jan. / mar. 2017.

Moreira, J. M. M. Á. P. et al.

ISSN eletrônico 1982-4688

DOI: $10.5380 /$ rf.v47i1.47687 
Tabela 6. Evolução da balança comercial dos produtos florestais.

Table 6. Evolution of the trade balance in forest products.

\begin{tabular}{|c|c|c|c|c|c|c|c|c|c|}
\hline \multirow[t]{2}{*}{ Ano } & \multicolumn{3}{|c|}{$\begin{array}{c}\text { Brasil } \\
\text { (Bilhões US\$) }\end{array}$} & \multicolumn{3}{|c|}{$\begin{array}{l}\text { Agronegócio } \\
\text { (Milhões US\$) }\end{array}$} & \multicolumn{3}{|c|}{$\begin{array}{l}\text { Produtos Florestais } \\
\text { (Milhões US\$) }\end{array}$} \\
\hline & Exportações & Importações & Saldo & Exportações & Importações & Saldo & Exportações & Importações & Saldo \\
\hline 2004 & 96,677 & 62,836 & 33,842 & $39.035,31$ & $4.835,76$ & $34.199,56$ & $6.693,64$ & $1.080,57$ & $5.613,07$ \\
\hline 2005 & 118,529 & 73,600 & 44,929 & $43.623,38$ & $5.112,05$ & $38.511,33$ & $7.202,08$ & $1.222,76$ & $5.979,32$ \\
\hline 2006 & 137,807 & 91,351 & 46,457 & $49.471,02$ & $6.698,64$ & $42.772,38$ & $7.886,05$ & $1.631,17$ & $6.254,88$ \\
\hline 2007 & 160,649 & 120,617 & 40,032 & $58.431,40$ & $8.732,27$ & $49.699,13$ & $8.822,84$ & $1.950,34$ & $6.872,51$ \\
\hline 2008 & 197,942 & 172,985 & 24,958 & $71.837,33$ & $11.880,65$ & $59.956,67$ & $9.332,30$ & $2.569,30$ & $6.762,99$ \\
\hline 2009 & 152,995 & 127,722 & 25,272 & $64.785,62$ & $9.900,47$ & $54.885,14$ & $7.227,10$ & $1.747,10$ & $5.480,01$ \\
\hline 2010 & 201,915 & 181,768 & 20,147 & $76.441,94$ & $13.398,89$ & $63.043,05$ & $9.281,43$ & $2.843,96$ & $6.437,47$ \\
\hline 2011 & 256,040 & 226,247 & 29,793 & $94.967,65$ & $17.507,98$ & $77.459,67$ & $9.637,05$ & $3.437,29$ & $6.199,76$ \\
\hline 2012 & 242,578 & 223,183 & 19,395 & $95.814,18$ & $16.409,10$ & $79.405,08$ & $9.067,49$ & $2.818,11$ & $6.249,37$ \\
\hline 2013 & 242,179 & 239,621 & 2,558 & $99.967,78$ & $17.060,58$ & $82.907,21$ & $9.634,77$ & $2.673,04$ & $6.961,73$ \\
\hline 2014 & 225,101 & 229,060 & $-3,959$ & $96.747,88$ & $16.613,85$ & $80.134,03$ & $9.950,71$ & $2.472,01$ & $7.478,70$ \\
\hline
\end{tabular}

Fonte: AgroStat (BRASIL, 2015a) e AliceWeb2 (BRASIL, 2015b).

O setor florestal manteve a sua participação absoluta no saldo da balança comercial brasileira relativamente constante na última década, com uma leve tendência de alta nos últimos dois anos, sendo o quarto maior setor do agronegócio neste quesito (Figura 1).

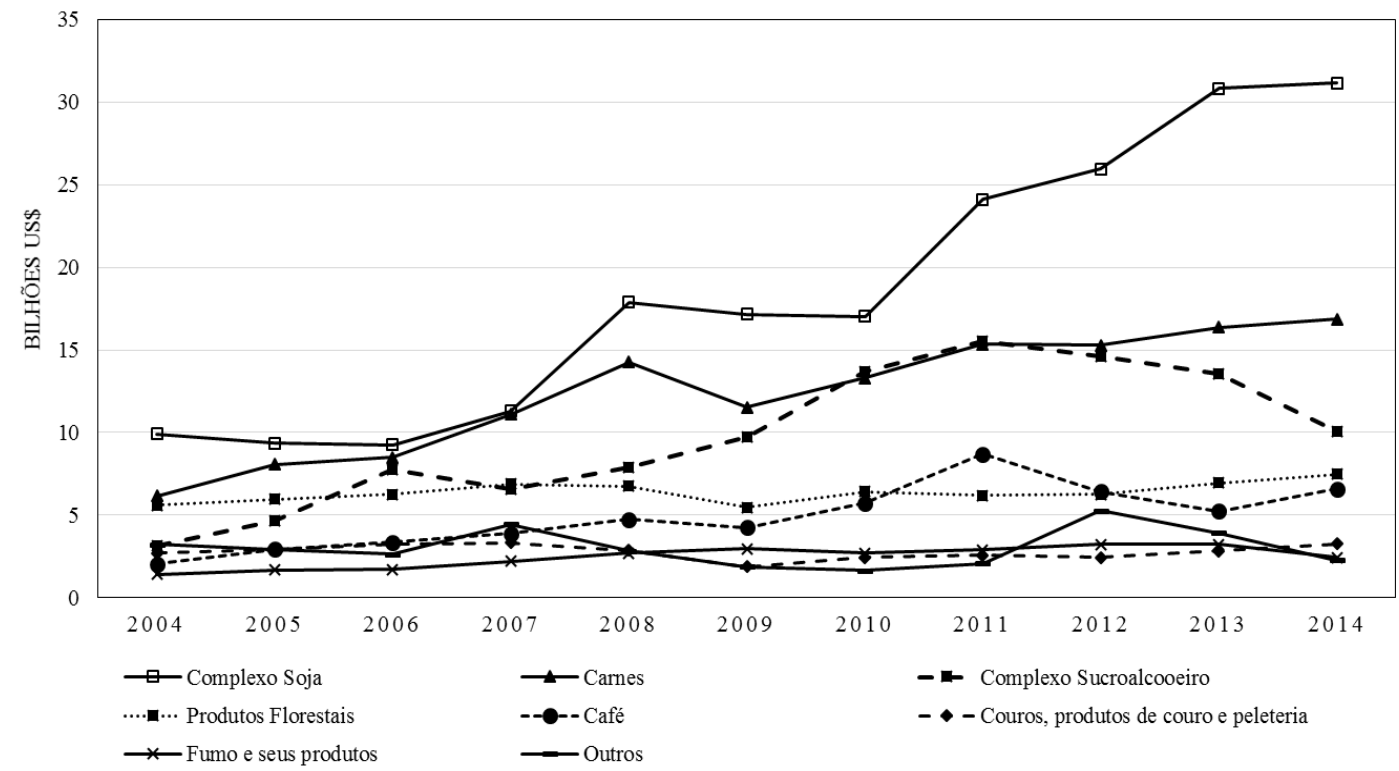

Figura 1. Saldo da balança comercial dos principais setores do agronegócio.

Figure 1. Trade balance of the main sectors of agribusiness.

Fonte: AliceWeb2 (BRASIL, 2015b).

A figura 2 permite observar comportamentos diferentes nos setores da produção florestal. $\mathrm{O}$ saldo dos setores de papel e borracha natural tem apresentado uma leve tendência de queda ao longo do período. O saldo dos produtos de madeira apresentou uma queda de patamar entre 2007 e 2009, com uma leve tendência de alta nos últimos dois anos. O setor de celulose foi o responsável pela manutenção do saldo dos produtos florestais na balança comercial, mesmo sentindo os reflexos da crise de 2009, manteve uma leve tendência de alta. Entretanto, a TGM de crescimento do saldo após 2010 caiu de maneira significativa quando comparada à TGM de crescimento entre 2004 e 2008, passando de 24,25\% ao ano no primeiro período para 2,93\% ao ano no segundo período.

A alteração no comportamento do saldo da balança comercial dos setores de celulose e dos produtos de madeira inspira um olhar mais detalhado sobre o seu comportamento e quais medidas podem ser adotadas para aumentar a sua competividade. Outra informação que chama atenção é o constante déficit no setor de borracha natural, indicando que o Brasil não é autossuficiente na produção de borrachas naturais. 


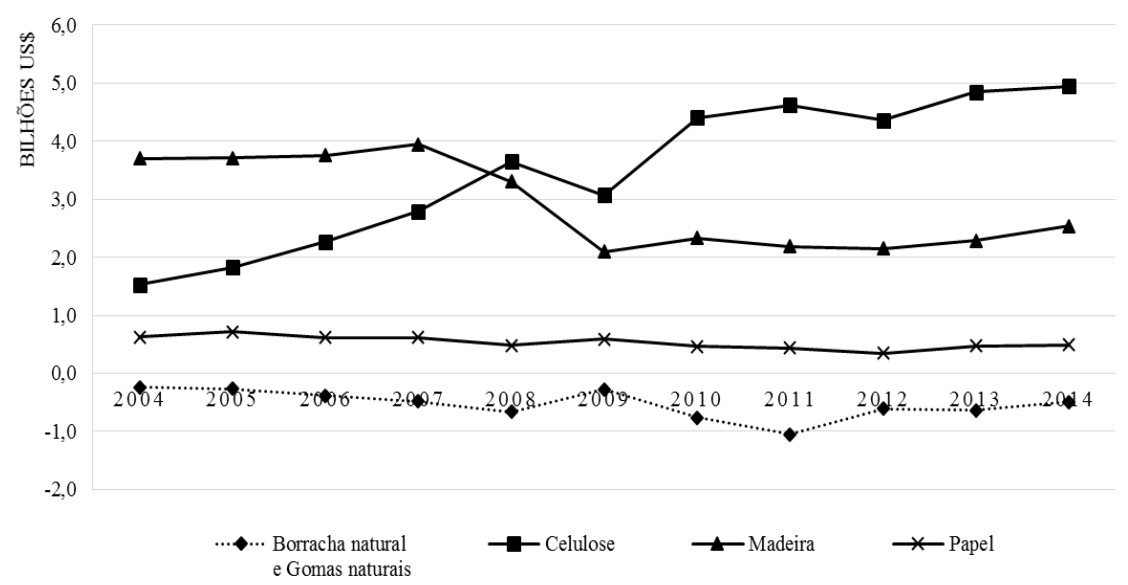

Figura 2. Saldo da balança comercial dos principais setores da produção florestal.

Figure 2. Trade balance of the main sectors of forestry production.

Fonte: AliceWeb2 (BRASIL, 2015b).

A evolução da geração de empregos diretos pelos segmentos da produção florestal podem ser observados na tabela 7 , sendo que o setor florestal de maneira geral (florestas plantadas e nativas) contribuiu com uma média anual superior a 650 mil empregos formais no país (SNIF, 2015), sendo que o maior potencial de geração de emprego não está na atividade florestal no campo, mas nas atividades posteriores ao longo da sua cadeia produtiva, nos processos de transformação e agregação de valor ao produto florestal. Entre os empregos diretos gerados na produção florestal, o setor de florestas plantadas foi responsável por quase $90 \%$ dos empregos diretos gerados na atividade primária florestal.

Tabela 7. Número de empregos formais por segmento do setor florestal (mil empregos).

Table 7. Number of formal jobs per segment of the forestry sector (1,000 jobs).

\begin{tabular}{|c|c|c|c|c|c|c|c|c|c|c|}
\hline Segmento do setor florestal & 2006 & 2007 & 2008 & 2009 & 2010 & 2011 & 2012 & 2013 & 2014 & 2015 \\
\hline $\begin{array}{l}\text { Atividades de apoio à } \\
\text { produção florestal }\end{array}$ & 59,2 & 60,8 & 52,4 & 44,4 & 53,1 & 54,5 & 47,3 & 39,9 & 38,5 & 33,0 \\
\hline Desdobramento de madeira & 101,0 & 99,2 & 87,9 & 83,1 & 87,6 & 85,2 & 81,3 & 78,1 & 75,7 & 70,7 \\
\hline Produção de celulose e papel & 154,4 & 158,7 & 161,4 & 163,2 & 173,2 & 175,1 & 177,2 & 181,6 & 184,8 & 177,3 \\
\hline $\begin{array}{l}\text { Produção de estruturas e } \\
\text { artefatos de madeira }\end{array}$ & 44,4 & 45,4 & 45,1 & 43,7 & 47,6 & 48,5 & 48,7 & 48,4 & 47,5 & 44,0 \\
\hline $\begin{array}{l}\text { Produção de lâminas e chapas } \\
\text { de madeira }\end{array}$ & 52,2 & 50,8 & 45,1 & 39,5 & 42 & 41,2 & 40,6 & 40,9 & 40,6 & 37,9 \\
\hline $\begin{array}{l}\text { Produção florestal - florestas } \\
\text { nativas }\end{array}$ & 8,7 & 8,7 & 6,4 & 6,4 & 7,2 & 8,2 & 8,4 & 7,4 & 8,3 & 7,7 \\
\hline $\begin{array}{l}\text { Produção florestal - florestas } \\
\text { plantadas }\end{array}$ & 51,4 & 62,5 & 65,5 & 62,9 & 69,5 & 70,3 & 66,7 & 64,5 & 62,5 & 63,1 \\
\hline Produção moveleira & 160,1 & 168,1 & 171,2 & 172,7 & 188,2 & 196,6 & 204,7 & 207,2 & 208,5 & 191,9 \\
\hline Total & 631,5 & 654,1 & 634,9 & 615,9 & 668,3 & 679,7 & 675,0 & 668,0 & 666,4 & 625,6 \\
\hline
\end{tabular}

A capacidade de geração de empregos do setor florestal foi confirmada por Nadjberg e Pereira (2004), que estimaram o potencial de geração de empregos de 41 setores da economia brasileira caso houvesse um aumento de produção de $\mathrm{R} \$ 10$ milhões em cada um deles. O setor de madeira e mobiliário e o setor de celulose, papel e gráfica ocupariam o quinto e o vigésimo lugar dentre todos 41 setores analisados, respectivamente. $\mathrm{O}$ setor da indústria da borracha ocuparia a trigésima terceira posição. $\mathrm{O}$ aumento dos plantios florestais com foco em múltiplo uso, além de possuírem uma maior rentabilidade para os produtores, tem a possibilidade de ofertar matéria-prima para os dois principais setores florestais na geração de emprego, podendo dar uma importante contribuição para o desenvolvimento social e econômico do país.

\section{DISCUSSÃO}

Apesar de o Brasil apresentar vantagens comparativas para a produção florestal em relação aos demais países, dentre as quais, destaca-se a maior produtividade de coníferas e folhosas em plantios florestais com foco na produção de madeira (IBA, 2014) os dados históricos apresentados na tabela 1 evidenciam uma tendência de

FLORESTA, Curitiba, PR, v. 47, n. 1, p. 85 - 94, jan. / mar. 2017.

Moreira, J. M. M. Á. P. et al.

ISSN eletrônico 1982-4688

DOI: $10.5380 /$ rf.v47i1.47687 
queda na participação global, dada a sua TGM inferior à média mundial. Nesse aspecto, considerando dados de uma série histórica mais abrangente apresentados na tabela 2, nota-se que o crescimento das florestas plantadas foi positivo até o final da década de 80, enquanto vigoravam políticas de incentivo econômico para implantação de florestas (KENGEN, 2001), com posterior queda da área após a redução desses incentivos. Considerando a área plantada em 2014, de 7.736 mil ha (IBA, 2014), percebe-se que houve um incremento da área plantada de 1.770 mil hectares no período de 29 anos (1985-2014).

O avanço da área plantada de florestas no Brasil deve-se, sobretudo, ao aumento da fronteira florestal de silvicultura para produção de celulose e papel e para produção de energia. De acordo com Andrade Guerra et al. (2015), em um estudo de prospeç̧ão para a geração de energia no Brasil, a biomassa é apontada como uma possível fonte de energia renovável, principalmente com o aproveitamento de resíduos de outros processos de transformação, o que caracteriza um fator propulsor para o aumento de florestas plantadas. De acordo com Ceccon e Miramontes (2008), as plantações florestais para a produção de biomassa têm um considerável impacto sobre as economias regionais no Brasil, envolvendo desde indústrias de grande escala como também pequenos agricultores. Os autores avaliaram que a promoção de associações e parcerias florestais, têm contribuído significativamente para o aumento do mercado de trabalho e criação de novas fontes de renda, além de um importante papel na redução do desmatamento, na preservação do meio ambiente e na utilização mais racional dos recursos naturais.

O baixo valor anual das florestas plantadas obtido na tabela $3(\mathrm{R} \$ 1.854,34)$ condiz com a realidade, pelo menos para a maioria dos plantios florestais, uma vez que as atividades florestais geralmente não conseguem se inserir em locais onde o custo de oportunidade da terra é elevado, dada a sua condição de uso e produtividade agrícola. A viabilidade econômica da atividade florestal é significativamente influenciada pelo o preço da terra, constituindo-se em um dos principais fatores que comprometem os indicadores.

É importante destacar que em função das significativas oscilações de clima e nos mercados, sobretudo dos preços, a rentabilidade das culturas agrícolas e florestais pode sofrer alteração, modificando o rank entre as culturas analisadas na tabela 4. Como exemplo, pode-se citar a avaliação realizada por Ribeiro e Silva (2008) comparando as culturas de eucalipto, café, mandioca e pecuária de corte, na qual mostrou que o cultivo florestal de eucalipto é viável economicamente, porém ocupa a terceira posição, depois do café e da mandioca. Em outros casos, como a situação da pequena propriedade rural do centro-sul do Paraná analisada por Viana et al. (2014), o eucalipto foi mais atrativo do que as atividades de soja e milho. Vitale e Miranda (2010) também observaram melhor resultado econômico do Eucalyptus dunnii em relação ao de Pinus taeda na região centro-sul do Paraná, explicado pela maior receita e em um período de tempo menor.

Vale salientar que o sistema de cultivo escolhido no presente trabalho foi objetivando a produção de lenha, sendo este um dos mais simples e com baixa agregação de valor à floresta. Sistemas de produção mais longos com foco no uso múltiplo (madeira serrada, celulose, lenha, etc.) apresentam rentabilidades superiores aos cultivos focados em um único produto, mas exigem uma maior profissionalização dos produtores para que possam atender mercados mais exigentes, que pagam melhores preços pela produção florestal. De acordo com FAMATO (2013), o cultivo de eucalipto para madeira serrada no Mato Grosso do Sul apresentou um VPLA superior, em pelo menos $34 \%$, quando comparado com o plantio de eucalipto para a produção de lenha. Em sistemas agroflorestais, devido ao lucro obtido pelas culturas agrícolas, Magalhães et al. (2014) concluíram que é mais viável economicamente antecipar o corte das árvores e reiniciar o sistema, dado que a receita da cultura agrícola proporciona aumento do VPL do sistema.

Nestes cenários, o planejamento da produção e um estudo de mercado por parte do produtor rural é de extrema importância antes de iniciar o empreendimento florestal. O preço da madeira em pé sofre forte dependência dos custos de colheita e transporte da madeira. Mesmo que o produtor venda a madeira em pé, o comprador terá que colhê-la e transportá-la, sendo estas duas atividades bastante onerosas na produção florestal. Conforme Oliveira et al (2008), pequenas variações no preço da madeira afetam de maneira significativa a rentabilidade de cultivos florestais. Além disso, plantios realizados em longas distâncias do mercado consumidor dificilmente terão condições de obter uma boa remuneração pela sua madeira, especialmente se o foco da produção for biomassa para celulose ou energia (OLIVEIRA et al, 2008). Souza et al. (2011) chama atenção que, além da distância, a produtividade e as características da floresta influenciam diretamente no custo final da madeira colhida. Para Ceccon e Miramontes (2008), o acesso ao crédito e o manejo florestal adequado são as principais dificuldades que as empresas e os pequenos agricultores enfrentam.

No que tange a importância econômica das atividades desenvolvidas de modo geral pelo setor florestal brasileiro, os resultados do presente trabalho refletem claramente os benefícios sobre o aspecto comercial e na geração de empregos. Estudo semelhante foi realizado por Levá et al. (2016) na República Checa, onde os autores constataram através da análise de índices de rentabilidade de 55 empresas florestais que, em termos médios, o setor pode ser considerado rentável, muito embora notou-se grande variabilidade dos valores. 


\section{CONCLUSÕES}

- As florestas plantadas podem representar investimentos atrativos para os produtores rurais, com ganhos semelhantes aos da agricultura, desde que bem planejadas antes da sua implantação.

- O preço da madeira em pé sofre forte influência dos custos de colheita e transporte, devendo os mesmos serem avaliados no momento da idealização do projeto, e não após a sua implementação, faltando um ou dois anos para a idade de corte.

- O segmento de florestas plantadas destaca-se no Brasil pelo seu elevado impacto social e econômico. A atividade apresenta alto potencial de expansão, com geração de renda e emprego, principalmente ao longo da sua cadeia produtiva de transformação da madeira, incrementando a obtenção líquida de divisas para o país.

- O segmento também possui uma área de plantio razoável, mas ainda pouco explorada em relação ao seu potencial produtivo e a disponibilidade de terras para cultivos florestais.

- O aumento das florestas plantadas, principalmente aquelas destinadas ao uso múltiplo, podem trazer desenvolvimento social e econômico, com geração de emprego, renda e divisas às várias localidades no país, notadamente às regiões que possuem extensas áreas degradadas que poderiam ser convertidas em plantios florestais.

\section{REFERÊNCIAS}

ASSOCIAÇÃO BRASILEIRA DE PRODUTORES DE FLORESTAS PLANTADAS (ABRAF). Anuário estatístico da ABRAF: ano base 2005. Brasília: ABRAF, 2006. Disponível em: <http://www.ipef.br/estatisticas/ relatorios/anuario-ABRAF-2006.pdf> Acesso em: 13 dez. 2016.

ANDRADE GUERRA, J. B. S. O. de; DUTRA, L., SCHWINDEN, N. B. C.; ANDRADE, S. F. de. Future scenarios and trends in energy generation in Brazil: supply and demand and mitigation forecasts. Journal of Cleaner Production, v. 103, p. 197-210, 2015.

BRASIL. Ministério da Agricultura, Pecuária e Abastecimento. AGROSTAT - Estatísticas de comércio exterior do agronegócio brasileiro. Disponível em: <http://sistemasweb.agricultura.gov.br/pages/AGROSTAT. html>. Acesso em: 04 maio 2015a.

BRASIL. Ministério do Desenvolvimento, Indústria e Comércio Exterior. ALICEWEB2 - Sistema de análise das informações de comércio exterior. Disponível em: 〈http://aliceweb.mdic.gov.br/>. Acesso em: 04 maio $2015 b$.

CECCON, E.; MIRAMONTES, O. Reversing deforestation? Bioenergy and society in two Brazilian models. Ecological Economics, v. 67, p. 311-317, 2008.

CENTRO DE DESENVOLVIMENTO DO AGRONEGÓCIO (CEDAGRO). Coeficientes técnicos e custos de produção na agricultura do estado do Espírito Santo, 2015. Disponível em: <http://www.cedagro.org.br/ coeficiente_planilhas.php >. Acesso em: 11 maio 2015.

COMPANHIA NACIONAL DE ABASTECIMENTO (CONAB). Custos de produção. 2015a. Disponível em: <http://www.conab.gov.br/conteudos.php?a=1546\&t=2>. Acesso em: 30 abr. 2015.

Indicadores da agropecuária. Brasília, Ano XXII, n. 01, jan. 2015b, p. 01-92. Disponível em: <http://www.conab.gov.br/OlalaCMS/uploads/arquivos/15_02_18_17_40_51_revista_janeiro_2015.pdf>. Acesso em: 05 maio 2015.

FEDERAÇÃO DA AGRICULTURA E PECUÁRIA DO ESTADO DE MATO GROSSO (FAMATO). Diagnóstico de florestas plantadas do Estado de Mato Grosso. Cuiabá: Instituto Mato-Grossense de Economia Agropecuária (IMEA), 2013.

FOOD AND AGRICULTURE ORGANIZATION (FAO). Forest resource assessment - FRA 2015: terms and definitions. Rome: FAO, 2015. (Working Paper 180). Disponível em: <http://www.fao.org/docrep/017/ap 862e/ap862e00.pdf>. Acesso em 21 jul. 2015.

Global forest resource assessment 2010: main report. Rome: FAO, 2010 (Forestry Paper 163). Disponível em: <http://www.fao.org/docrep/013/i1757e/i1757e.pdf>. Acesso em: 07 maio 2015.

INDÚSTRIA BRASILEIRA DE ÁRVORES (IBA). Indústria brasileira de árvores 2014. Disponível em: <http://www.iba.org/shared/iba_2014_pt.pdf>. Acesso em: 15 maio 2015. 
INSTITUTO BRASILEIRO DE GEOGRAFIA E ESTATÍSTICA (IBGE). Produção agrícola municipal PAM. 2013. Disponível em: <ftp://ftp.ibge.gov.br/Producao_Agricola/Producao_Agricola_Municipal_[anual] /2013/xls/Tabela_Temp Instituto Brasileiro de Geografia e Estatística._Perm_15_xls.zip>. Acesso em: 10 mai 2015.

Produção da extração vegetal e da silvicultura - PEVS, 2014. Disponível em: <ftp://ftp.ibge.gov.br/Producao_Agricola/Producao_da_Extracao_Vegetal_e_da_Silvicultura_[anual]/2013/xls/b rasil_xls.zip>. Acesso em: 15 mai 2015.

Séries históricas e estatísticas - utilização das terras (ha), 2015. Disponível em: $<$ http://seriesestatisticas.ibge.gov.br/series.aspx $? \mathrm{no}=1 \& \mathrm{op}=0 \& v$ codigo $=\mathrm{AGRO} 03 \& \mathrm{t}=u$ tilizacao-terras-ha>. Acesso em: 09 mai 2015.

KENGEN, S. A política florestal brasileira: uma perspectiva histórica. Porto Seguro: Série Técnica IPEF, $\mathrm{n}$. 34, 2001. p. 18-34.

LEVÁ, M.; CERMÁKOVÁ, H.; STÁROVÁ, M.; VOSTROVSKÁ, H. The assessment of forestry companies in the Czech Republic with focus on profitability. Journal of Forest Science, v. 62, n. 3, p. 116-125, 2016.

LIMA, E. A. de; SILVA, H. D. da; TUSSOLINI, E. L. Potencial do Eucalyptus benthamii para produção de carvão em fornos convencionais. Colombo: Embrapa Florestas, 2012. 4p. (Embrapa Florestas, Comunicado Técnico, 305).

MAGALHÃES, J. G. de S.; SILVA, M. L. da; SALLES, T. T.; REGO, L. J. S. Análise econômica de sistemas agroflorestais via uso de equações diferenciais. Revista Árvore, v. 38, n. 1, p. 73-79, 2014.

NAJBERG, S.; PEREIRA, R. de O. Novas estimativas do modelo de geração de empregos do BNDES. Sinopse econômica, n. 133, 2004.

OLIVEIRA, A. D. de; FERREIRA, T. C.; SCOLFORO, J. R. S.; MELlO, J. M. de; REZENDE, J. L. P. Avaliação econômica de plantios de Eucalyptus grandis para a produção de celulose. Revista Cerne, v. 14, n. 1, p. 82-91, 2008.

RIBEIRO, S. C.; SILVA, M. L. da. Viabilidade econômica de atividades florestais e agropecuárias. Revista de Política Agrícola, n. 2, p. 76-85, 2008.

SISTEMA NACIONAL DE INFORMAÇÕES FLORESTAIS (SNIF). Número de empregos formais por segmento do setor florestal. Disponível em: 〈http://www.florestal.gov.br/snif/producao-florestal/emprego〉. Acesso em: 14 mai 2015.

SOUZA, M. A. de; PIRES, C. B.; SILVEIRA, F. C. Análise de custos de prestação de serviços de colheita florestal mecanizada. Organizações Rurais \& Agroindustriais, v. 13, n. 2, p. 270-289, 2011.

VIANA, G.; HOEFLICH, V. A.; MOROZINI, J. F.; SCHWANS, A. Análise de investimentos em projetos de agronegócios: um estudo comparativo entre culturas tradicionais e a cultura florestal de eucalipto na mesorregião centro-sul do Paraná. Custos e @gronegócio on line, v. 10, n. 4, p. 241-265, 2014.

VITALE, V.; MIRANDA, G. de M. Análise comparativa da viabilidade econômica de plantios de Pinus taeda e Eucalyptus dunni na região centro-sul do Paraná. FLORESTA, v. 40, n. 3, p. 469-476, 2010. 